\title{
Analysis of macrophage subtypes and annexin A1 expression in lesions of patients with cutaneous leishmaniasis
}

\author{
Joselina Maria da Silva ${ }^{[1],[2], ~ H e l e n ~ A g u i a r ~ L e m e s ~ d a ~ S i l v a ~}{ }^{[1]}$, Carolina Zelenski ${ }^{[2]}$, \\ Jéssica Azevedo de Moraes Souza ${ }^{[3],}$ Marcia Hueb ${ }^{[4]}$ and Amílcar Sabino Damazo ${ }^{[1],[2],[5]}$
}

[1]. Universidade Federal de Mato Grosso, Faculdade de Medicina, Pós-Graduação em Ciências da Saúde, Cuiabá, MT, Brasil.

[2]. Universidade Federal de Mato Grosso, Faculdade de Medicina, Laboratório de Histologia, Cuiabá, MT, Brasil.

[3]. Universidade Federal de Mato Grosso, Faculdade de Medicina, Laboratório de Genética, Cuiabá, MT, Brasil.

[4]. Universidade Federal de Mato Grosso, Departamento de Medicina Interna, Cuiabá, MT, Brasil.

[5]. Universidade Federal de Mato Grosso, Faculdade de Medicina, Departamento de Ciências Básicas em Saúde, Cuiabá, MT, Brasil.

\begin{abstract}
Introduction: Cutaneous leishmaniasis is caused by protozoa of the genus Leishmania and transmission occurs through the bite of sandflies. It is an infectious disease, which affects skin and mucosa. The aim was to quantify the macrophages M1 and M2 and the annexin A1 expression in the skin lesions of patients with cutaneous leishmaniasis. Methods: Skin biopsies from patients (n $=50$ ) were analyzed and classified according to the lesion type as: exudative cellular reaction, exudative granulomatous reaction, exudative necrotic reaction, exudative necrotic-granulomatous reaction. Using the immunofluorescence technique, macrophages were identified by CD163 marker, differentiated by anti-MHCII and anti-CD206 antibodies, and annexin A1 expression was determined by arbitrary unit (a.u.) densitometry. Results: In M1 macrophages, a greater expression of this protein was observed in the exudative cellular reaction type lesions $(136.3 \pm 2.6$ a.u., assuming mean and standard derivation) when compared to the expression in the lesions of exudative granulomatous reaction, exudative necrotic reaction and exudative necrotic-granulomatous reaction patients $(108.0 \pm 2.3,121.6 \pm 3.2$ and $124.7 \pm 2.4$ a.u., respectively). Regarding M2 macrophages, it was observed that patients with exudative cellular reaction lesion also had a higher expression of this protein (128.8 \pm 2.6 a.u.), when compared to the expression in the lesions of exudative granulomatous reaction, exudative necrotic reaction and exudative necrotic-granulomatous reaction patients $(105.6 \pm 2,113.9 \pm 2.8,114.3 \pm 2.1$ a.u., respectively). Conclusions: These data suggest that annexin A1 is assisting macrophages in the phagocytosis process of patients with exudative cellular reaction lesion type.
\end{abstract}

Keywords: Cutaneous leishmaniasis. Annexin A1. Macrophages.

\section{INTRODUCTION}

American tegumentary leishmaniasis (ATL) is a tropical and non-contagious disease, and is caused by protozoa belonging to the genus Leishmania, which presents a complex biological cycle. Leishmaniasis can be transmitted between humans or other vertebrate hosts through the bite of infected female sandflies, with the Lutzomyia genus being the main vector. In Brazil, seven Leishmania species cause the disease and are

Corresponding author: Prof. Dr. Amilcar Sabino Damazo.

e-mail: asdamazo@yahoo.com.br

Orcid: 0000-0003-2323-008X

Received 26 July 2019

Accepted 13 November 2019 distributed throughout the national territory. The three main species are Leishmania (V) braziliensis, $L$. (V.) guyanensis and L. (L.) amazonensis ${ }^{1-3}$.

The most frequently used diagnosis method is the association between the clinical aspects presented by the patient and the results of parasitological exams. However, these tests have low specificity and sensitivity. The application of methods such as polymerase chain reaction (PCR) and immunofluorescence could help to increase the sensitivity of these exams ${ }^{4-6}$.

Macrophages are cells known for their great heterogeneity and plasticity, as they may present different phenotypes in response to different microenvironmental stimuli. They are classified in several groups according to their functions, with groups M1 and M2 being the most important ${ }^{7}$. After stimulation 
with cytokines associated with Th1 lymphocytes, notably IFN $\gamma$, they acquire effector function against intracellular pathogens, which is called the classical pathway or M1 phenotype. Conversely, in the milieu of cytokines associated with Th2 lymphocytes, for example, IL-4, IL-13, IL-33, TGF- $\beta$, and IL-10, or via microbial triggers, M2 polarization (alternative route) will occur ${ }^{8,9}$. The macrophage polarization mechanisms have been widely classified as M1 (classical pathway) and M2 (alternative pathway), where M1 polarized cells exhibit strong pro-inflammatory and microbicidal activity, while polarization in M2 is linked to the production of an anti-inflammatory milieu leading to tissue regeneration and wound healing ${ }^{10}$.

In lesions, increased production of pro-inflammatory cytokines, including IFN- $\gamma$ and TNF- $\alpha$, is essential for parasite control $^{11,12}$. At this stage, there may also be an adaptive immune response by $\mathrm{B}$ and $\mathrm{T}$ lymphocytes. From this point, the infection can develop into a disease or be successfully contained ${ }^{13}$. In addition to the immune response, mediating and facilitating molecules act to re-establish the homeostasis ${ }^{14}$. Among these, the annexin-A1 protein (ANXA1) stands out. as an important antiinflammatory mediator, endowed with a potent anti-migratory leukocyte activity, which ensures the transient nature of the inflammatory response $\mathrm{e}^{15,16}$. Thus, this study aimed to investigate the histopathological aspects of skin lesions and analyze the presence of M1 and M2 type macrophages at the leishmaniasis infection sites and their ANXA1 expression.

\section{METHODS}

\section{Patients}

Patients $(\mathrm{n}=50)$ with a diagnosis of cutaneous leishmaniasis (CL) attended the Leishmaniasis Outpatient Clinic of the Júlio Müller University Hospital (UHJM), Federal University of Mato Grosso (UFMT), located in Cuiabá-MT. The patients had a mean age of 47 years (range, 18 to 83 years). The criteria of eligibility for participating in this study were: having no other infectious or chronic-degenerative diseases, no immunosuppressive status, and have not received treatment for leishmaniasis.

Forty of the studied patients were males $(80 \%)$. The higher number of infected males coincides with the literature, which suggests that there is a higher risk of infection for such individuals as a result of their prevalence among rural laborers, as well as their leisure habits ${ }^{17}$.

As for ethnicity, 20 patients were white $(40 \%), 15$ were black (30\%) and 15 were brown (30\%). The predominance of white patients is different from most of the samples described in the literature ${ }^{17,18}$. However, in the state of Mato Grosso, there is a large number of people who migrated from the southern region of the country to work in rural properties, which may explain the higher number of infected white people in this context ${ }^{19}$.

Skin lesions were mostly reported in the lower limbs (54\%) and presented features such as raised borders (50\%), infiltration ( $82 \%$ ) and ulceration (74\%), well-described characteristics of lesions caused by leishmaniasis ${ }^{20-22}$.

\section{Ethical considerations}

Participants who agreed to be part of the study initially signed the Free and Informed Consent Term approved by the Research Ethics Committee of the UHJM, protocol no. CEEA no. 51430915.0.0000.55.41. All procedures followed the Helsinki Declaration.

\section{Laboratory tests}

To test for leishmaniasis, the following techniques were performed: parasitological culture of tissue samples from biopsy and aspiration of the injuries edges; scraping blade, aspirate, and biopsy imprint; histopathology of the biopsy and polymerase chain reaction (PCR) of samples from the lesions edges.

The site asepsis was performed with iodized topical solution and then $0.9 \%$ saline solution; the clean area was infiltrated with an anesthetic (lidocaine 2\%), and aspiration was performed using a syringe and needle.

Scraping was performed at the inner border of the cutaneous lesion. A slide containing the sample was stained with Giemsa and examined.

The aspiration was performed from the outer edge of the lesion, at the site of the greatest infiltration. The aspirated material was deposited on a glass slide.

For the aspirate culture, the material was added to a $15 \%$ rabbit blood agar plate.

The fragment culture obtained from a biopsy was also added to a $15 \%$ rabbit blood agar plate.

The imprint examination was performed with a fragment of the biopsy. Several pressure movements were performed by the apposition of the biopsy fragment on the surface of the slide.

From the laboratory tests performed, the most reliable data were obtained by scraping (70\% positivity) and PCR (100\% positivity) tests (Table 1). It is possible to notice that when compared to PCR, the other tests, which are the most frequently used, present less specificity and sensitivity ${ }^{4,5}$. However, they are necessary, mainly because most of Mato Grosso countryside cities do not have the equipment and/or expertise to carry out PCR exams. Since leishmaniasis is a notifiable disease and requires confirmation of the case to be notified, it is essential to perform these tests, to obtain at least one positive result to initiate treatment ${ }^{4,23}$.

\section{Sample collection with a cervical brush}

The samples for the PCR were collected using cervical brushes that were placed in direct contact with the lesions. At the time of collection, the brushes were conditioned in a $1.5 \mathrm{~mL}$ microtube containing phosphate-buffered saline (PBS).

\section{Extraction of deoxyribonucleic acid (DNA) from skin fragment}

DNA extraction from the cervical brushes was performed using commercial Invitrogen ${ }^{\circledR}$ kits following the manufacturer's recommendations, which included a previous step of proteinase $\mathrm{K}$ digestion. The extracted DNA was quantitated using a spectrophotometer Nanodrop $2000^{\circledR}$ (ThermoScientific, USA) . 
TABLE 1: Laboratory data of patients with cutaneous leishmaniasis.

\begin{tabular}{|c|c|c|}
\hline Variables analyzed & Quantity & Percentage \\
\hline \multicolumn{3}{|l|}{ Scraping blade } \\
\hline Positive & 35 & $70 \%$ \\
\hline Negative & 13 & $26 \%$ \\
\hline Inconclusive & 2 & $4 \%$ \\
\hline \multicolumn{3}{|l|}{ Printing plate } \\
\hline Positive & 24 & $48 \%$ \\
\hline Negative & 20 & $40 \%$ \\
\hline Inconclusive & 6 & $12 \%$ \\
\hline \multicolumn{3}{|l|}{ Aspirant blade } \\
\hline Positive & 23 & $46 \%$ \\
\hline Negative & 23 & $46 \%$ \\
\hline Inconclusive & 4 & $8 \%$ \\
\hline \multicolumn{3}{|l|}{ Fragment Culture } \\
\hline Positive & 15 & $30 \%$ \\
\hline Negative & 11 & $22 \%$ \\
\hline Inconclusive & 24 & $48 \%$ \\
\hline \multicolumn{3}{|l|}{ Culture of aspirate } \\
\hline Positive & 11 & $22 \%$ \\
\hline Negative & 9 & $18 \%$ \\
\hline Inconclusive & 30 & $60 \%$ \\
\hline \multicolumn{3}{|l|}{ PCR } \\
\hline Positive & 50 & $100 \%$ \\
\hline
\end{tabular}

\section{Identification of Leishmania species in patients through PCR-HSP70C}

The method used to identify the Leishmania species was PCR-HSP70C ${ }^{24}$. For each reaction, it was used a mixture with a final volume of $30 \mu \mathrm{L}$ containing $3 \mu \mathrm{L}$ of buffer, $3 \mu \mathrm{L}$ of dNTPs, $1.8 \mu \mathrm{L}$ of magnesium chloride at $1.5 \mathrm{mM}, 6.2 \mu \mathrm{L}$ of DNA, $0.6 \mu \mathrm{L}$ of the first Forward 5 'GGA CGAGATCGAGCGCATGGT3', 0.6 $\mu \mathrm{L}$ of primer Reverse 5'TCCTTCGACGCCTCCTGGTTG3', and $0.3 \mu \mathrm{L}$ of $\mathrm{GoTaq}^{\circledR} \mathrm{DNA}$ polymerase, together with $14.5 \mu \mathrm{L}$ of Milli-Q water. For the PCR assays, the following amplification cycle was used: $94{ }^{\circ} \mathrm{C}$ for 4 min, followed by 33 cycles of 94 ${ }^{\circ} \mathrm{C}$ for $15 \mathrm{sec}, 58^{\circ} \mathrm{C}$ for $45 \mathrm{sec}, 72^{\circ} \mathrm{C}$ for $30 \mathrm{sec}$, and a final extension at $72{ }^{\circ} \mathrm{C}$ for $10 \mathrm{~min}$.

Subsequently, PCR-HSP70C products were subjected to $2 \%$ agarose gel electrophoresis to visualize the resulting PCR bands. The negative control consisted of samples without DNA.

\section{Identification of Leishmania species in patients through RFLP PCR}

HSP70C positive PCR products were incubated at $37^{\circ} \mathrm{C}$ overnight with Hae III and BstUI enzymes separately for digestion. For each reaction, mixture was prepared with the following reagents: $1 \mu \mathrm{L}$ of an enzyme, $2 \mu \mathrm{L}$ of the buffer, 9 $\mu \mathrm{L}$ of ultrapure water $\left(\right.$ Invitrogen $^{\circledR}$ ) and $8 \mu \mathrm{L}$ of PCR product.

For all patients with positive results for the presence of the Leishmania parasite, the species identification was performed by PCR-RFLP. After the disclosure, we compared the band pattern of patients' samples with 6 references from the World Health Organization (WHO) and the Fundação Oswaldo Cruz (FIOCRUZ): Leishmania braziliensis (MHOM/BR/1975/ M2903/IOC/L566); Leishmania amazonensis (IFLA/BR/1967/ PH8/IOC/L575); Leishmania guyanensis (MHOM/BR/1975 /M4147/IOC/L); Leishmania lainsoni (MHOM/BR/1981/ M6426/IOC/L1023); Leishmania naiffi (MDAS/BR/1979/ M553/IOC/L1365); Leishmania shawi (MCEB/BR/1984/ M8408/IOC/L1545).

PCR-RFLP examination revealed that all the patients were infected with L. brasiliensis (Figure 1). In the study by Silva and collaborators ${ }^{25}$, it was also observed the prevalence of $L$. brasiliensis in CL patients from Cuiabá, MT, Brazil.

\section{Biopsy collection}

Initially, asepsis and local anesthesia (2\% lidocaine without vasoconstrictor) were performed at the border of the lesion that presented the greatest sign of clinical activity. The biopsy was carried out using a $4 \mathrm{~mm}$ punch. The sample was fixed in $4 \%$ paraformaldehyde, diluted in PBS, and transported to the histology laboratory of the Faculty of Medicine. The sample was washed in the same buffer, dehydrated in solution with increasing ethanol concentration, clarified in xylene and included in paraffin.

\section{Histopathological analysis}

Subsequently, the samples were sectioned $(3 \mu \mathrm{m})$ using the HIRAX M60 microtome (Carl Zeiss, Germany). The sections were then placed on histological slides and, after deparaffinization and rehydration, stained with hematoxylineosin with differentiation for histopathological analysis. The histopathological classification of the lesion types was done by two independent researchers and is in agreement with the types described by Magalhães and collaborators ${ }^{26}$ : exudative cellular reaction (ECR); exudative necrotic reaction (ENR); exudative necrotic-granulomatous reaction (ENGR); exudative granulomatous reaction (EGR); exudative tuberculoid reaction (ETR).

\section{Quantification of endogenous ANXA1 protein expression and identification of cellular markers by the immunofluorescence technique}

For the detection of endogenous ANXA1 and macrophages subtypes, $3 \mu \mathrm{m}$ sections were prepared on slides with biological adhesive (BIOBOND) (British Biocell International, Cardiff, UK) and subsequently incubated with the following reagents at room temperature ${ }^{27}$ : (a) incubated in a water bath at $70{ }^{\circ} \mathrm{C}$ in $0.21 \%$ sodium citrate solution for $1 \mathrm{~h}$; (b) blocked with $3 \%$ hydrogen peroxide in $70 \%$ methanol for $1 \mathrm{~h}$; (c) permeabilized by incubation with $0.4 \%$ Tween 20 in PBS for 15 min; (d) 


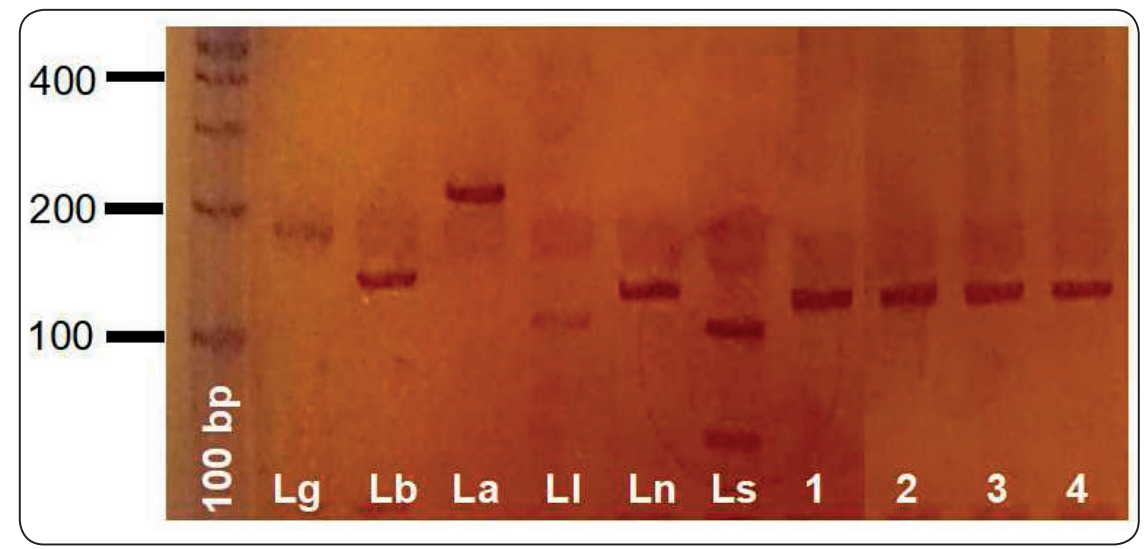

FIGURE 1: Determination of the Leishmania species by PCR-RFLP technique. Reference standard of the Leishmania species after the digestion of the products with the enzyme Hae III. Lg: Leishmania guyanensis Lb: Leishmania braziliensis; La: Leishmania amazonensis; LI: Leishmania lainsoni; Ln: Leishmania naiffi; Ls: Leishmania shawi. Samples of patients with cutaneous leishmaniasis (1-4)

blocked with $5 \%$ bovine serum albumin (BSA), diluted in PBS for $1 \mathrm{~h}$; (e) incubated with the primary antibodies for 18 $\mathrm{h}$ at $4{ }^{\circ} \mathrm{C}$ in a humid chamber. For detection of ANXA1, the following antibodies were used: rabbit anti-ANXA1 (Invitrogen, USA;1:200 in PBS/1\% BSA) to detect the macrophage CD163 marker; mouse anti-CD163 (Cell Marque, USA, clone EP152, 1:200); to identify M1 macrophages mouse anti-MHC II was used (sc-59318; Santa Cruz Biotechnology Inc., Santa Cruz, CA, 1:100); to identify M2 macrophages, mouse anti-CD206 (R \& D Systems, clone 309210, 1:50) was used. To identify primary antibodies, the following secondary antibodies were used: ALEXA FLUOR 488 fluorochrome conjugated goat antirabbit IgG (Invitrogen, USA, 1:200 in PBS/1\% BSA), goat antimouse IgG conjugated with fluorochrome ALEXA FLUOR 555 (Invitrogen, USA, 1:200 in PBS/1\% BSA), goat anti-mouse IgG conjugated to fluorochrome ALEXA FLUOR 647 (ABCAM, USA, 1:50 in PBS/1\% BSA), and DAPI (4',6-diamidino-2phenylindole) nuclear marker (Invitrogen ${ }^{\mathrm{TM}}$, USA) for $1 \mathrm{~h}$ at room temperature and in a darkroom; and (g) washed with PBS and mounted in citifluor (DAKO, USA). As a negative control, we used $1 \%$ BSA instead of the primary antibody.

Immunolabelled macrophages M1 and M2 were identified and quantified on the AxioScope A1 microscope (Carl Zeiss, GR) with the Axiovision Software (Carl Zeiss, GR). M1 macrophages were stained with CD163+/MHC II+ and M2 with CD163+/CD206+. Also, the DAPI stain was used to analyzed nucleus morphology. Macrophages number was expressed as mean \pm standard deviation (SD) per $\mathrm{mm}^{2}$ of skin tissue of CL patients. The same area was analyzed for both M1 and M2 macrophages. M2 has higher levels of CD206 and has a suppressed expression of MHC II, and the M1 has the opposite characteristics ${ }^{28}$.

ANXA1 protein expression was analyzed and quantified by average optical density with the aid of the same Software. To perform this measurement, several points of the cytoplasm of the macrophages were evaluated. This quantification was done according to the light spectrum [value arbitrarily assigned, ranging from 0 to 255 arbitrary units (a.u)]. ANXA1 values per macrophages were expressed as mean \pm standard deviation (SD) in the lesion of CL patients.

\section{Statistical analysis}

For all analyses performed, the data obtained were expressed as mean $\pm \mathrm{SD}$. The results obtained were statistically compared with the aid of the software GraphPad Prism 5 (La Jolla, CA, USA) through an analysis of variance (one-way ANOVA) with Bonferroni post-test. It was also analyzed the normality (Kolmogorov-Smirnov test) and homogeneity (Levene test) of the data. The significance level was set at 0.05 .

\section{RESULTS}

Histopathological data and analysis of the profile of macrophages subtypes and the mechanism of action of ANXA1

Patients' lesions were histopathologically classified by lesion type in ECR (76\%), ENR (6\%), EGR (14\%) and ENGR (4\%) (Figure 2).

In the immunofluorescence analysis was assessed the presence of the M1 subtype macrophages (CD163+/MHC II + ) (Figure 3A-D) and the M2 subtype (CD163+/CD206+) (Figure 3E-H) and quantified expression of ANXA1 protein in these cells.

It was observed that patients with ENR lesions have a higher number of M1 macrophages when compared to that of other lesion types. M2 macrophages were more numerous in patients with ECR lesion when compared to other lesion types (Table 2).

Evaluating the expression of ANXA1 in macrophages M1 (Figure 3A-D), an increase of this protein expression was observed in the cells of patients with ECR type lesion. In contrast, the EGR type lesions presented a lower expression (Table 2).

In M2 type macrophages (Figure 3E-H), an increase in the expression of ANXA1 in the ECR lesion type was observed. 


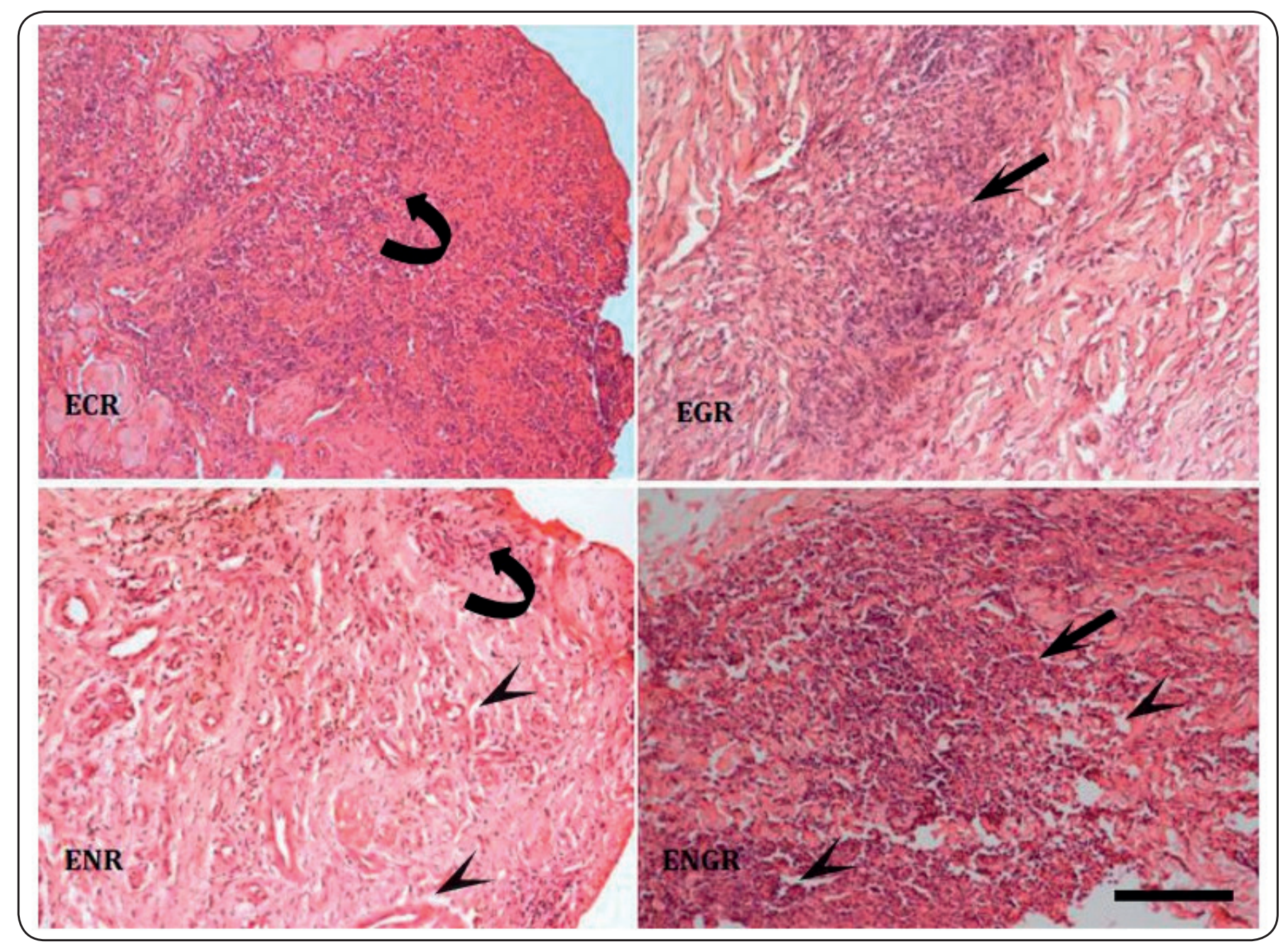

FIGURE 2: Histopathological characteristics of lesions present in cutaneous leishmaniasis. ECR shows leukocyte infiltration (curved arrow). EGR shows the presence of a granuloma (arrow). ENR shows leukocyte infiltration and necrosis (arrowheads). ENGR shows the presence of a granuloma (arrow). ENR shows necrosis (arrowheads) and the presence of a granuloma (arrow). Stain: Hematoxylin and eosin stain (HE). Bar $=50 \mu \mathrm{m}$.

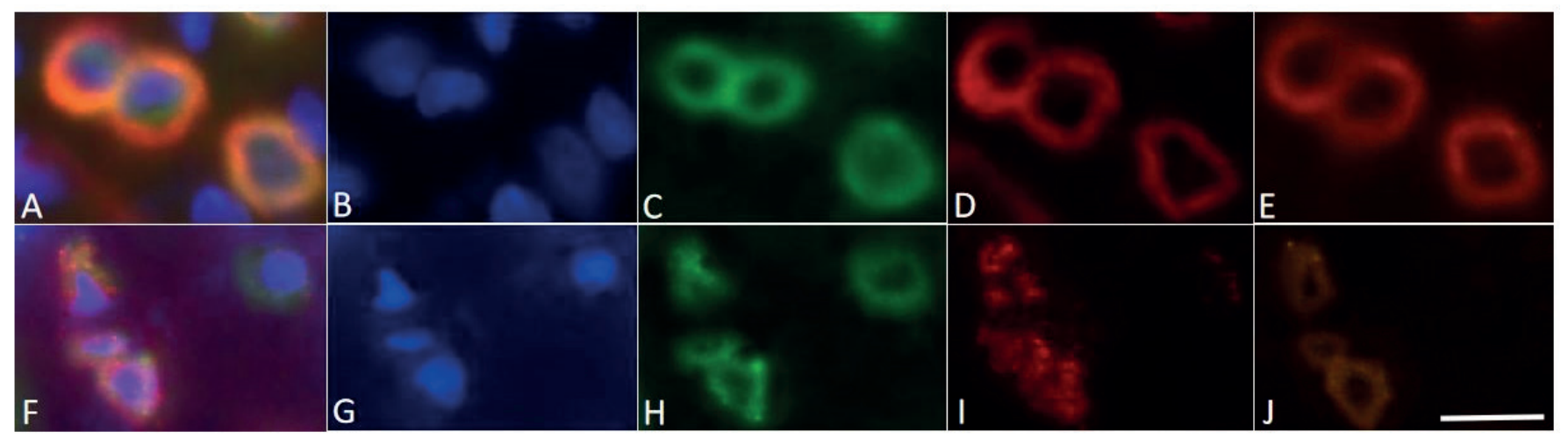

FIGURE 3: Immunofluorescence analysis for ANXA1 in the skin of patients with leishmaniasis evidencing macrophages type M1 and M2. (A and F) Merge images, (B and G) DAPI, (C and H) ANXA1, (D and I) CD163, (E) CD206 (J) MHC II. Bar $=10 \mu \mathrm{m}$. 
TABLE 2: Mean number of macrophages and expression of ANXA1 in types M1 and M2 in skin lesions of patients with leishmaniasis.

\begin{tabular}{|c|c|c|c|c|}
\hline $\begin{array}{l}\text { Type of } \\
\text { injury }\end{array}$ & Macrophage M1 & Macrophage M2 & Macrophage M1 & Macrophage M2 \\
\hline & \multicolumn{2}{|c|}{ Cell number (cells/ mm2) } & \multicolumn{2}{|c|}{ ANXA1 expression (a.u.) } \\
\hline ECR & $32.6 \pm 1.9^{\#}$ & $42.0 \pm 3.4$ & $136.3 \pm 2.6$ & $128.8 \pm 2.6$ \\
\hline ENR & $45.1 \pm 2.8$ & $24.4 \pm 2.0++$ & $121.6 \pm 3.2^{* * *}$ & $113.9 \pm 2.8^{* * *}$ \\
\hline \multirow[t]{3}{*}{ ENGR } & $25.5 \pm 3.2^{+++}$ & $27.3 \pm 4.4+$ & $124.7 \pm 2.4^{* \star *}$ & $114,3 \pm 2.1^{* * *}$ \\
\hline & ${ }^{\#} P<0,05$ ENR vs. ECR & ${ }^{*} P<0,05$ ECR vs. EGR & ${ }^{* * *} P<0,001$ vs. ECR & ${ }^{* * *} P<0,001$ vs. ECR \\
\hline & ${ }^{+++} P<0,001$ ENR vs. ENGR & ${ }^{+} P<0,05$ ECR vs. ENGR & ${ }^{+++} P<0,001$ ENGR vs. EGR & \\
\hline
\end{tabular}

Number assuming mean and SD.

The other lesion types results did not show statistical differences (Table 2).

\section{DISCUSSION}

The inflammatory response triggered during cutaneous leishmaniasis (CL) is dependent on the release of specific mediators, which leads to a pattern of specific immune response $^{29,30}$. Macrophages play an important role in the initial response against Leishmania infection, and its activation profile is decisive for the resolution or non-resolution of the infection. In this inflammatory scenario, several mediators act to maintain the homeostasis of infected tissue, and among these mediators, the ANXA1 protein is an especially important one because of its high regulatory capacity. In this study, we emphasize the importance of a better understanding of the ANXA1 action and the profile of macrophages involved in leishmaniasis, to contribute to a better understanding of this disease and to the elaboration of therapeutic alternatives for the patients.

The histopathological analysis showed that most of the patients had ECR lesions, possibly because they were recent lesions with 1 to 4 months of evolution. This result is observed when there is a rapid diagnosis and consequent treatment of the disease, and the University Hospital Júlio Muller is a reference to treat leishmaniasis in the state of Mato Grosso, Brazil. For this reason, patients with leishmaniasis who seek early care do not present chronic lesions, which would exhibit characteristics such as EGR, ENR or ENGR.

We further evaluated the presence of macrophages subtypes in histopathological lesions. Macrophages are crucial cellular elements in Leishmania infection as they can host parasites for long periods, act as antigen-presenting cells, secrete molecules that induce an inflammatory response, and act to eliminate parasites through the production of toxic oxygen derivatives and $\mathrm{NO}^{31}$. In agreement with the data of Silva and collaborators ${ }^{22}$, this work shows that there is ANXA1 expression in the skin macrophages of patients infected by $L$. brasiliensis.

In the immunofluorescence analyzes, a ratio of $1: 2$ for M1:M2 macrophages could be observed in the ECR lesions. Macrophages polarized in M2 act by an alternative pathway that may cause less tissue damage compared to the classical pathway, which acts primarily through the release of $\operatorname{ROS}^{32}$. Concerning the histopathological patterns present in ECR lesions, it is the first standard reaction to the presence of the parasite in the tissue $^{29}$. In these lesions, the predominance of M2 macrophages could lead to an effective action of the immune system to destroy the parasite without causing great damage to the tissue.

The ENR lesions, characterized by the presence of tissue necrosis, showed an increase in the ratio of 2:1 of M1 to M2 macrophages. In this histopathological condition, the presence of M1 macrophages could be more effective for destruction from both the necrotic cells and the parasite, as widely described in the literature ${ }^{33-35}$.

As one of the regulatory mediators of macrophages, we evaluated the expression of the ANXA1 in M1 and M2 cells. This work demonstrated increased levels of ANXA1 in the ECR type lesions in both M1 and M2 macrophages. It is interesting to note that this protein, besides functioning as an immune regulating agent, also acts as an inducer of phagocytosis. Yona et al. ${ }^{36}$ have demonstrated in their experiments that the absence of ANXA1 in macrophages from transgenic animals is functionally related to a reduced rate of phagocytosis. Therefore, the high 
expression of ANXA1 in M1 and M2 macrophages in ECR type lesions suggests a high phagocytic activity of these cells.

On the contrary, it was noted that the expression of this protein is lower in EGR lesions, which are characterized by the presence of granulomatous reaction ${ }^{29}$. In this type of reaction, the rate of phagocytosis would be reduced, and the release of cytokines increased, thus justifying the lower amount of ANXA1 in this type of lesion in both M1 and M2 macrophages.

In conclusion, we observed that polarization of the M2 macrophages in ECR lesions and M1 type in ENR are crucial for the organism defense against infection by Leishmania. In addition, ANXA1 presence in both M1 and M2 macrophages in ECR type lesions suggests the participation of this protein in the initial phagocytosis process of Leishmania. The reduced expression of ANXA1 in macrophages M1 and M2 in lesions of the EGR type suggests activation of macrophages to produce pro-inflammatory factors in this type of lesion.

\section{Financial Support}

This work was supported by the Research Support Foundation of Mato Grosso (Fundação de Amparo a Pesquisa de Mato Grosso, FAPEMAT) protocol n ${ }^{\circ}$ 226574/2013 (EDITAL PPSUS/ FAPEMAT N ${ }^{\circ}$. 002/2013), and the Faculty of Medicine, Federal University of Mato Grosso, Cuiabá, MT, Brazil. ASD is supported by the Brazilian National Council for Scientific and Technological Development (Conselho Nacional de Desenvolvimento Científico e Tecnológico, CNPq) (ASD grant number: 3132249/2017-2).

\section{Conflict of Interest}

The authors declare that there is no conflict of interest

\section{REFERENCES}

1. Carvalho MLR, Andrade ASR, Fontes CJF, Hueb M, Silva SO, Melo MN. Leishmania (Viannia) braziliensis is the prevalent species infecting patients with tegumentary leishmaniasis from Mato Grosso State, Brazil. Acta Trop. 2006; 98(3):277-5.

2. Arraes SMAA, Marini MT, Martello D, Silveira TGV, Lonardoni MVC, Nanni MR. Investigação sorológica de casos subclínicos de leishmaniose tegumentar após um surto em uma localidade endêmica. Rev Soc Bras Med Trop. 2008;41(2):205-8.

3. Gomes AHSS, Armelin IM, Menon SZ, Pereira-Chioccola VL. Leishmania (V.) brasiliensis: Detection by PCR in biopsies from patients with cutaneous leishmaniasis. Exp Parasitol. 2008;119(3):319-24.

4. Masmoudí A, Hariz W, Marrekchi S, Amouri M, Turki H. Old World cutaneous leishmaniasis: diagnosis and treatment. J Dermatol Case Rep. 2013;7(2):31-41.

5. Pourmohammadi B, Motazedian MH, Hatam GR, Kalantari M, Habibi P, Sarkari B. Comparison of three methods for diagnosis of cutaneous leishmaniasis. Iran J Parasitol. 2010;5(4):1-8.

6. Gontijo B, Carvalho MLR. Leishmaniose tegumentar americana. Rev Soc Bras Med Trop, 2003;36(1):71-80.

7. Movahedi K, Laoui D, Gysemans C, Baeten M, Stangé G, Van den bossche J, et. al. Different tumour microenvironments contain functionally distinct subsets of macrophages derived from Ly6C(high) monocytes. Cancer Res. 2010;70(14):5728-39.
8. Pearce EJ, Macdonald AS. The immunobiology of schistosomiasis. Nat Rev Immunol. 2002;2(7):499-11.

9. Martinez FO, Helming L, Gordon S. Alternative activation of macrophages: an immunologic functional perspective. Annu Rev Immunol. 2009;27(1):451-83.

10. Mukhopadhyay D, Mukherjee S, Roy S, Dalton JE, Kundu S, Sarkar A, et al. M2 Polarization of monocytes-macrophages is a Hallmark of Indian post-kala-Azar dermal leishmaniasis. PLoS Negl Trop Dis. 2015;9(10):e0004145.

11. de Oliveira CI, Brodskyn CI. The immunobiology of Leishmania braziliensis infection. Front Immunol. 2012;3(1):145. doi: 10.3389/ fimmu.2012.00145

12. Santos CS, Brodskyn CI. The role of CD4 and CD8 T cells in human cutaneous leishmaniasis. Front Public Health. 2014;2(1):1-6.

13. Gollob, KJ, Viana AG, Dutra WO. Immunoregulation in human American leishmaniasis: balancing pathology and protection. Parasite Immunol. 2014;36(8):367-76.

14. Basil, MC, Levy BD. Specialized pro-resolving mediators: endogenous regulators of infection and inflammation. Nat Rev Immunol. 2016;16(1):51-67.

15. Perretti M. Endogenous mediators that inhibit the leukocyteendothelium interaction.Trends Pharmacol Sci. 1997;18(11):418-25.

16. Perretti M, Flower RJ. Annexin 1 and the biology of the neutrophil. J Leukoc Biol. 2004;76(1):25-9.

17. Ministério da Saúde (MS). Secretaria de Vigilância em Saúde. Sistema Nacional de Vigilância em Saúde - Manual de vigilância da leishmaniose tegumentar, Secretaria de Vigilância em Saúde, Departamento de Vigilância das Doenças Transmissíveis. Brasília: MS; 2017.19 p.

18. Ministério da Saúde (MS). DATASUS [Internet]. 2019 [cited 2019 nov 19]. Available from: http://tabnet.datasus.gov.br/cgi/tabcgi. exe?sinannet/cnv/ltabr.def.

19. Instituto brasileiro de geografia e estatística (IBGE). Censo Agropecuário, [Internet] 2017. [Updated 2017 mar 05; cited 2019 nov 19]. Available from: https://cidades.ibge.gov.br/brasil/mt/ pesquisa/24/76693.

20. Hartley MA, Kohl K, Ronet C, Fasel N. The therapeutic potential of immune cross-talk in leishmaniasis. Clin Microbiol Infect. 2012;19(2):119-30.

21. Guenin-macé L, Oldenburg R. Pathogenesis of skin ulcers: lessons from the Mycobacterium ulcerans and Leishmania spp. Pathogens. Cell Mol Life Sci. 2014;71(13):2443-50.

22. Ministério da saúde (MS). Guia de Vigilância em Saúde: Secretaria de Vigilância em Saúde, Coordenação Geral de Desenvolvimento da Epidemiologia e Serviços. $3^{\circ}$ edição. Brasília: MS; 2019. 489p.

23. Ministério da saúde (MS). Portaria $\mathrm{n}^{0}$ 204, de 18 de fevereiro de 2016. Define a Lista Nacional de Notificação Compulsória de doenças, agravos e eventos de saúde pública nos serviços de Saúde públicos e privados em todo o território nacional, nos termos do anexo, e dá outras providências Diário Oficial da União. $18 \mathrm{fev}$ 2016;Seção 1:23.

24. da Graça CG, Volpini AC, Romero GAS, Oliveira-neto MP, Hueb M, Porrozzi R, et al. Development and validation of PCR-based assays for diagnosis of American cutaneous leishmaniasis and identification of the parasite species. Mem Inst Oswaldo Cruz. 2012;107(5):664-74.

25. Silva HAL, Lima GS, Boité MC, Porrozzi R., Hueb M, Damazo AS. Expression of annexin A1 in Leishmania-infected skin and 
its correlation with histopathological features. Rev Soc Bras Med. 2015;48(5):560-7.

26. Magalhães AV, Moraes MAP, Raick AN, Llanos-cuentas A, Costa JML, Cuba CC, et al. Histopathology of cutaneous leishmaniasis caused by Leishmania braziliensis braziliensis. Rev Inst Med Trop Sao Paulo. 1986;28(6):421-30.

27. Damazo AS, Paul-clark MJ, Straus AH, Takahashi HK, Parretti M, Oliani SM. Analysis of the annexin 1 expression in rat trachea:study of the mast cell heterogeneity. Annexins. 2004;1(1):12-8.

28. Bose D, Banerjee S, Chatterjeee N, Das S, Saha M, Saha KD. Inhibition of TGF- $\beta$ induced lipid droplets switches M2 macrophages to M1 phenotype. Toxicol in vitro. 2019;58(1):207-14.

29. Lima, HC, Vasconcelos AW, David JR.; Lerner EA. American cutaneous leishmaniasis: in situ characterization of the cellular immune response with time. Am J Trop Med Hyg. 1994;50(6):7 43-47.

30. Awasthi A, Mathur RK, Saha B. Immune response to Leishmania infection. Indian J Med Res. 2004;119(6):238-58.
31. Giudice A, Vendrame C, Bezerra C, Carvalho LP, Delavechia T, Carvalho EM, et al. Macrophages participate in host protection and the disease pathology associated with Leishmania braziliensis infection. BMC Infect Dis. 2012;12(1):75-84.

32. Atri C, Guerfali FZ, Laouini D. Role of Human Macrophage Polarization in Inflammation during Infectious Diseases. Int J Mol Sci. 2018;19(6):1801-16.

33. Gordon, S, Martinez FO. Alternative activation of macrophages: mechanism and functions. Immunity. 2010;32(5):593-04.

34. Li Y, Cai L, Wang H, Wu P, Gu W, Chen Y, et al. Pleiotropic regulation of macrophage polarization and tumorigenesis by formyl peptide receptor-2. Oncogene. 2011;30(36):3887-99.

35. Liu Y, Zou X, Chai Y, Yao Y. Macrophage Polarization in Inflammatory Diseases. Int J Biol Sci. 2014;10(5):520-29.

36. Yona S, Heinsbroek SEM., Peiser L, Gordon S, Perretti M, Flower RJ. Impaired phagocytic mechanism in annexin 1 null macrophages. Br J Clin Pharmacol. 2006;148(4):469-77. 